\title{
Geological and Geobotanical Studies of Long Valley Caldera, CA, USA, Utilizing New 5m Hyperspectral Imagery
}

B.A. Martini, E.A. Silver, D.C. Potts, W.L. Pickles

This article was submitted to IEEE International Geoscience and Remote Sensing Symposium, Honolulu, HI, July 24-28, 2000

July 1, 2000 


\section{DISCLAIMER}

This document was prepared as an account of work sponsored by an agency of the United States Government. Neither the United States Government nor the University of California nor any of their employees, makes any warranty, express or implied, or assumes any legal liability or responsibility for the accuracy, completeness, or usefulness of any information, apparatus, product, or process disclosed, or represents that its use would not infringe privately owned rights. Reference herein to any specific commercial product, process, or service by trade name, trademark, manufacturer, or otherwise, does not necessarily constitute or imply its endorsement, recommendation, or favoring by the United States Government or the University of California. The views and opinions of authors expressed herein do not necessarily state or reflect those of the United States Government or the University of California, and shall not be used for advertising or product endorsement purposes.

This is a preprint of a paper intended for publication in a journal or proceedings. Since changes may be made before publication, this preprint is made available with the understanding that it will not be cited or reproduced without the permission of the author.

This report has been reproduced directly from the best available copy.

Available to DOE and DOE contractors from the

Office of Scientific and Technical Information

P.O. Box 62, Oak Ridge, TN 37831

Prices available from (423) 576-8401

http:/ / apollo.osti.gov/bridge/

Available to the public from the National Technical Information Service

U.S. Department of Commerce 5285 Port Royal Rd., Springfield, VA 22161

http://www.ntis.gov/

OR

Lawrence Livermore National Laboratory Technical Information Department's Digital Library http:/ /www.llnl.gov/tid/Library.html 


\title{
Geological and Geobotanical Studies of Long Valley Caldera, CA, USA Utilizing New 5m Hyperspectral Imagery
}

\author{
B. A. Martini*, E. A. Silver*, D. C. Potts ${ }^{+}$, W. L. Pickles ${ }^{\#}$ \\ ${ }^{*}{ }^{+}$University of California, Santa Cruz, ${ }^{*}$ Earth Science Dept., ${ }^{+}$Biology Dept., 1156 High St., Santa Cruz, CA 95064, \\ tel:(831)459-2830, fax:(831)459-3074, bmartini@es.ucsc.edu, esilver@es.ucsc.edu, potts@biology.ucsc.edu
} "Lawrence Livermore National Lab, 7000 East Ave., L-182, Livermore, CA 94550-9517, tel:(925)422-7812,
fax:(925)422-3925, pickles1 @ llnl.gov

\section{INTRODUCTION}

In May of 1989, a six month-long small magnitude earthquake swarm began beneath the Pleistocene-aged dacitic cumulovolcano Mammoth Mountain. The following year, increased mortality of trees in the Horseshoe Lake region was observed. Their deaths were initially attributed to the Sierran drought of the 1980's. In 1994 however, soil gas measurements made by the USGS confirmed that the kills were due to asphyxiation of the vegetation via the presence of $30-96 \% \mathrm{CO}_{2}$ in ground around the volcano[1]. Physiological changes in vegetation due to negative inputs into the ecological system such as anomalously high levels of magmatic $\mathrm{CO}_{2}$, can be seen spectrally. With this phenomena in mind, as well as many other unanswered geological and geobotanical questions, seven lines of hyperspectral 5-meter HyMap data were flown over Long Valley Caldera located in eastern California on September 7, 1999, (see Fig. 1). HyMap imagery provides the impetus to address geobotanical questions such as where the treekills are currently located at Mammoth and other locales around the caldera as well as whether incipient kills can be identified. The study site of the Horseshoe Lake treekills serves as a focus to the initial analyses of this extensive HyMap dataset due to both the treekill's geologically compelling origins and its status as a serious volcanic geohazard.

\section{BACKGROUND AND SETTING}

Mammoth Mountain sits on the western rim of the much larger Long Valley caldera which formed 760,000 years ago in one of the most violent eruptions in earth history, expelling over $600 \mathrm{~km}^{3}$ of ash and lava. It is one of three active calderas within the contiguous United States. The most recent eruptive activity in the Long Valley region occurred along the north-south trending Mono-Inyo volcanic chain in the western part of the caldera. Eruptions as young as $\sim 600$ yrs. have occurred as part of this system, including on the northern flanks of Mammoth Mtn. The past twenty years have witnessed not only the previously mentioned localized volcanic degassing, but also increased seismic activity throughout the caldera beginning with four magnitude $~ 6.0$ events in 1980. Reinflation of the caldera's resurgent dome totals almost a meter since 1980 [2]. As a restless caldera,

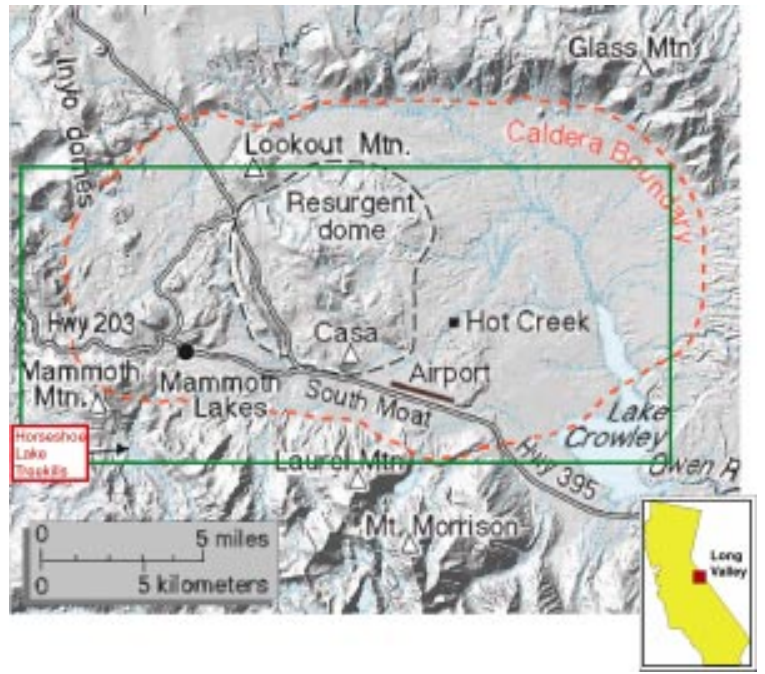

Figure 1. Index map of study region. Green box indicates boundaries of 1999 HyMap acquistion. Modified from USGS LVO website http://quake.wr.usgs.go/VOLCANOES/LongValley/

Long Valley has garnered abundant research and monitoring efforts, including whole suites of geophysical and geochemical analyses and studies. These efforts have culminated in the recent inception of the USGS's Long Valley Observatory in 1999. However, few remote sensing studies have been completed at this caldera, though Advanced Visible Infrared Imaging Spectrometer (AVIRIS) work by both de Jong in 1996 and Hausback and others in 1998 suggested initial success at mapping tree mortality in the vicinity of Mammoth Mtn.[3][4].

The Horseshoe Lake kill lies on the southern flank of Mammoth Mtn and is characterized by Quaternary andesites, dacites and glacial tills. The main kill mapped in this study lies exclusively on till. The dominant tree species found in the Horseshoe Lake region is Pinus contorta (Lodgepole Pine). Other species include Abies magnifica (Red Fir), Tsuga mertensiana (Mountain Hemlock), and Pinus albicaulis (Whitebark Pine). Flux from the Horseshoe Lake treekill region has declined from 350 tons/day in 1995 to 90 tons/day in 1998 [5]. The kill locations coincide with mapped faults. $\mathrm{CO}_{2}$ is thought to travel up along these faults from a semi-sealed low temperature gas reservoir that caps a much hotter liquid reservoir, and then spreads out into the soil near the surface [6]. 

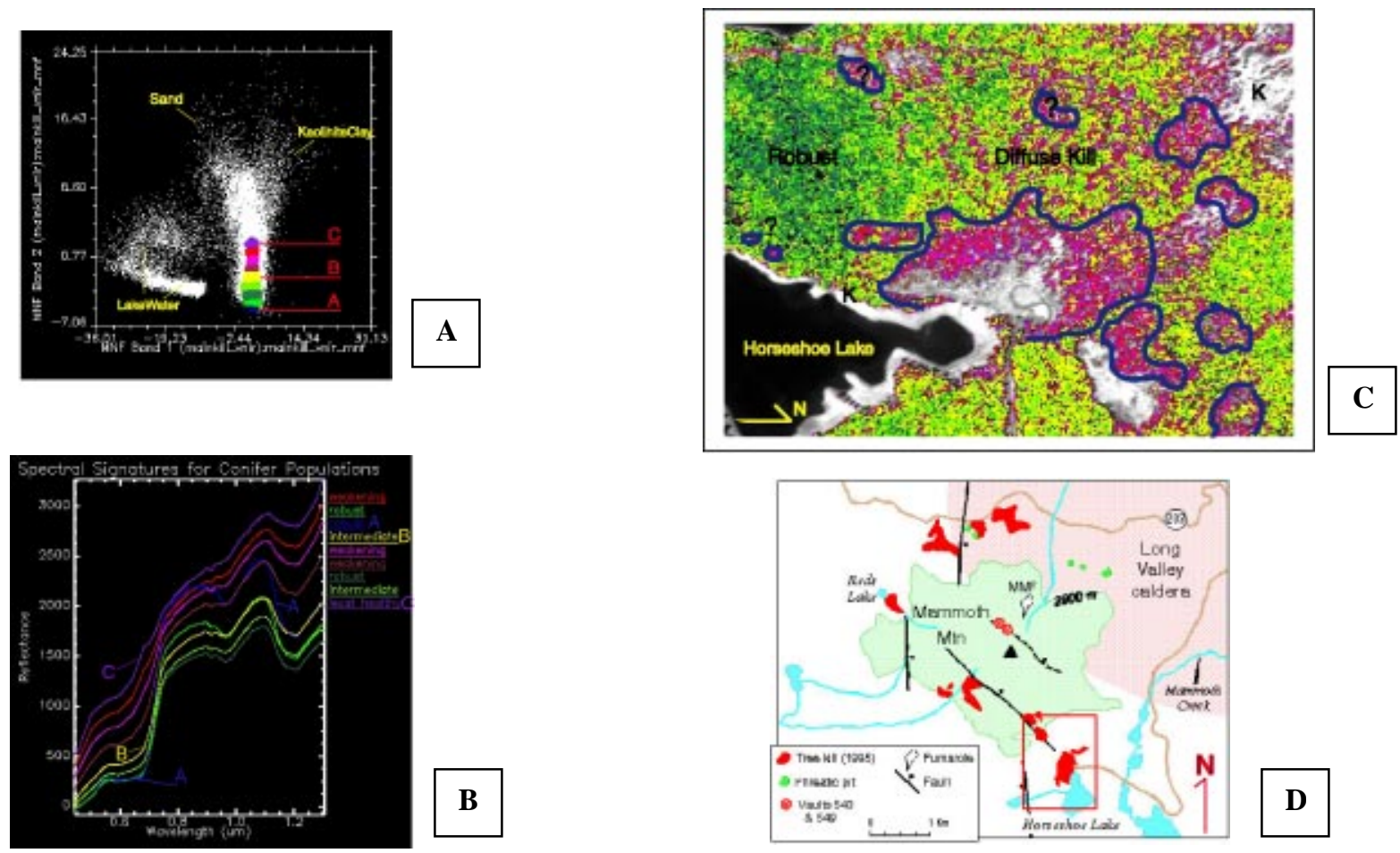

Figure 2.. Analysis of Horseshoe Lake treekill image subset. Fig. 2a shows the correlation between MNF Band 1 and 2. Letters coincide with letters shown in Fig. 2b. These spectra are means from the data shown in Fig. 2a. Fig. 2c shows spectrally mapped treekills. Kills with question marks indicate regions previously unmapped by more traditional methods. The letter $\mathrm{K}$ indicates concentrations of kaolinite, found predominately along faults. Fig. 2d is taken from the USGS LVO (Long Valley Observatory) website http://quake.wr.usgs.gov/VOLCANOES/LongValley/ and shows locations of tree kills mapped by previous workers. The red square shows location of image analysis in Fig. 2c.

Within the visible and near-infrared portions of the electromagnetic spectrum, absorptions due to pigments such as chlorophyll $\mathrm{A}$ and $\mathrm{B}$ contained within the leaves and needles of plants can change with respect to both positive and negative influences. In the case of the $\mathrm{CO}_{2}$-induced treekills around Mammoth, high levels of this gas causes asphyxiation of the organism which results in a breakdown of the metabolic processes and subsequently a loss in the chlorophyll absorption within the red wavelength region. This breakdown can be tracked spectrally.

\section{DATA ACQUISITION AND ANALYSIS}

The Australian HyMap sensor (Integrated Spectronics Ltd.) acquired images of the caldera at a five-meter spatial resolution with 126 bands across a spectral range of 450$2500 \mathrm{~nm}$ with bandwidths ranging from 10-20 nm. This whiskbroom scanner has a reported signal to noise ratio of greater than 1000:1. The sensor itself was flown in a twinengine Cessna with complete radiometric and spectral calibration on-board as well as simultaneous DGPS data acquisition used in image calibration and georectification.

This dataset was acquired as part of a group shoot that included several other U.S. governmental, educational, and commercial entities and was organized and administered by
Analytical Imaging and Geophysics (AIG) in Boulder, CO, USA and the HyVista Corporation in Sydney, AUS.

Analysis of this imagery was performed in the software package ENVI (Environment for Visualizing Images). The data was received atmospherically corrected via the ATREM (Atmospheric Removal) algorithm [6]. Further spectral smoothing of the data was performed with the EFFORT (Empirical Flat Field Optimal Reflectance Transformation) algorithm [7] by AIG. Unfortunately, same-day ground calibration was impossible, though some spectral measurements were made four days later with an ASD (Analytical Spectral Device) spectrometer.

In order to more efficiently analyze the huge files of these HyMap datacubes, we performed spatial subsetting by focusing on particular regions such as the Horseshoe Lake treekill. The data is then spectrally subset in two ways. In preparation for a principle components like algorithm called the Minimum Noise Fraction (MNF) contained within ENVI, the data cube is divided into two spectral chunks; a visiblenear infrared (VNIR) chunk (0.45-1.34 um) and a shortwave infrared (SWIR) chunk (1.39-2.50 um). The MNF algorithm contained within ENVI is then applied to each spectral chunk separately. The MNF is a two-step algorithm. The noise in the data is first whitened resulting in uncorrelated noise in every band and unit variance. Secondly, the data is treated to 
a standard principal components transform resulting in a set of new n-dimensional axes [8]. As we are only interested in those bands with the most signal and coherence, those bands containing mostly noise can be removed from further processing. The image subset presented in this paper produced approximately 20-22 coherent MNF bands.

Data analysis presented in this work ends with the study of the correlation between the first two MNF bands, or those bands that have the most signal and coherence, as well as contrast to each other. Figure 2 a shows MNF Band 1 on the $\mathrm{x}$-axis plotted against MNF Band 2 on the $\mathrm{y}$-axis. The spread of data nicely represents the major spectral populations of materials. By analyzing the correlation of Band 1 and Band 2 within the spectral tree population, we discriminated important classes of tree physiological condition as shown by the spectral signatures in Figure $2 b$. We then used these signatures to create the map seen in Figure 2c.

\section{RESULTS AND CONCLUSIONS}

Analysis of the MNF Band 1 and 2 correlation allows us to discriminate populations of trees due to their relative physiological state. The loss in the chlorophyll absorption in the red wavelengths is readily seen in the conifer population spectral plot. The progression from robust populations (A) at the bottom of the MNF plot (Fig. 2a) to those populations at an intermediate physiological state (B) is seen spectrally by a loss in the chlorophyll absorption as well as an overall decrease in near-infrared reflectance (Fig. 2b). Population C illustrates the least healthy vegetation in the image. The loss of chlorophyll in these populations is due primarily to anomalously high levels of soil- $\mathrm{CO}_{2}$. However, many other factors can lead to loss of chlorophyll. In this region, sickness due to beetle infestations has been observed. Drought and heat can cause a loss of chlorophyll. In short, many conditions affecting a plant's metabolic system can lead to a loss of chlorophyll. A priori knowledge is therefore required to narrow the sources of morbidity upon vegetation populations.

Our previous work on vegetation signatures has indicated that often, the linear spectral mixing between a rock and vegetation specimen can mimic a loss in chlorophyll such as that seen in Fig. 2b. However, analysis of the longer wavelengths of these physiological spectral classes in the 2$2.5 \mathrm{um}$ region indicated little evidence of rock-vegetation mixing. Populations such as $\mathrm{C}$ may have some mixing, especially as we approach that area of the MNF plot exemplifying clay and sand. The increased spatial resolution of HyMap (5m) over such imagery as AVIRIS (20m) has been valuable in geobotanical studies of the caldera because smaller pixels provide for less mixing and therefore more accurate classifications.

We successfully discriminated previously mapped treekill populations with the HyMap imagery as indicated in Fig. 2c and $2 \mathrm{~d}$. Most of the robust populations are located directly to the west of Horseshoe Lake. Past fieldwork suggests that the diffuse treekill mapped to the west by HyMap is a real feature. We will ascertain the validity of this zone and other possible kills in the coming summer 2000 field season.

Future work with the treekill populations will include advanced processing techniques such as those used with clay alteration mapping in this region. Spectral endmembers of predominately kaolinite, alunite, and montmorillinite have been mapped along both known and previously unknown faults on the southern flanks of Mammoth Mtn. The inherent variability in vegetation has made such advanced processing more difficult, but the identification of both physiological state and species is possible.

\section{REFERENCES}

[1] Farrar, C. D., Sorey, M. S., Evans, W. C., Howle, J. F., Kerr, B. D., Kennedy, B. M., King, C. -Y., and Southon, J. R., "Forest-killing diffuse $\mathrm{CO}_{2}$ emission at Mammoth Mountain as a sign of magmatic unrest", Nature, v. 376, 675-677, 1995.

[2] Langbein, J., Dzurisin, D., Marshall, G., Stein, R., and Rundle, J., "Shallow and peripheral sources of inflation revealed by modeling two-color geodimeter and leveling data from Long Valley Caldera, California, 19881992," Journal of Geophysical Research, v. 100, 12,49712,495, 1995.

[3] De Jong, S. M., "Surveying dead trees and $\mathrm{CO}_{2}$-induced stressed trees using AVIRIS in the Long Valley Caldera", in Summaries of the Sixth Annual JPL Airborne Earth Science Workshop. JPL Publication 96-, 67-74, 1996.

[4] Hausback, B. P., Strong, M., Farrar, C., and Pieri, D. "Monitoring of volcanogenic $\mathrm{CO}_{2}$-induced tree kills with AVIRIS image data at Mammoth Mountain", California, in Summaries of the Seventh Annual JPL Airborne Earth Science Workshop. JPL Publication 98-, 1998.

[5] Sorey, M. L., Evans, W. C., Kennedy, B. M., Farrar, C. D., Hainsworth, L. J., and Hausback, B., "Carbon dioxide and helium emissions from a reservoir of magmatic gas beneath Mammoth Mountain, California”, Journal of Geophysical Research, v. 103, 15,303-15,323, 1998.

[6] Gao, B. C., Heidebrecht, K.B., and Goetz, A.F.H., "Derivation of scaled surface reflectances from AVIRIS data", Remote Sensing of Environment, v. 44, 165178,1993 .

[7] Boardman, J., "Post-ATREM polishing of AVIRIS apparent reflectance data using EFFORT: a lesson in accuracy versus precision", in Summaries of the Seventh Annual JPL Airborne Earth Science Workshop, JPL Publication 97-21,1998.

[8] Green, A. A., Berman, M., Switzer, P., Craig, M. D., “A transformation for ordering multispectral data in terms of image quality with implications for noise removal", IEEE Transactions on Geoscience and Remote Sensing, v. 26, no.1, pp. 65-74, 1988. 
a standard principal components transform resulting in a set of new n-dimensional axes [8]. As we are only interested in those bands with the most signal and coherence, those bands containing mostly noise can be removed from further processing. The image subset presented in this paper produced approximately 20-22 coherent MNF bands.

Data analysis presented in this work ends with the study of the correlation between the first two MNF bands, or those bands that have the most signal and coherence, as well as contrast to each other. Figure 2a shows MNF Band 1 on the $x$-axis plotted against MNF Band 2 on the $y$-axis. The spread of data nicely represents the major spectral populations of materials. By analyzing the correlation of Band 1 and Band 2 within the spectral tree population, we discriminated important classes of tree physiological condition as shown by the spectral signatures in Figure $2 \mathrm{~b}$. We then used these signatures to create the map seen in Figure 2c.

\section{RESULTS AND CONCLUSIONS}

Analysis of the MNF Band 1 and 2 correlation allows us to discriminate populations of trees due to their relative physiological state. The loss in the chlorophyll absorption in the red wavelengths is readily seen in the conifer population spectral plot. The progression from robust populations (A) at the bottom of the MNF plot (Fig. 2a) to those populations at an intermediate physiological state (B) is seen spectrally by a loss in the chlorophyll absorption as well as an overall decrease in near-infrared reflectance (Fig. 2b). Population C illustrates the least healthy vegetation in the image. The loss of chlorophyll in these populations is due primarily to anomalously high levels of soil- $\mathrm{CO}_{2}$. However, many other factors can lead to loss of chlorophyll. In this region, sickness due to beetle infestations has been observed. Drought and heat can cause a loss of chlorophyll. In short, many conditions affecting a plant's metabolic system can lead to a loss of chlorophyll. A priori knowledge is therefore required to narrow the sources of morbidity upon vegetation populations.

Our previous work on vegetation signatures has indicated that often, the linear spectral mixing between a rock and vegetation specimen can mimic a loss in chlorophyll such as that seen in Fig. 2b. However, analysis of the longer wavelengths of these physiological spectral classes in the 22.5 um region indicated little evidence of rock-vegetation mixing. Populations such as $\mathrm{C}$ may have some mixing, especially as we approach that area of the MNF plot exemplifying clay and sand. The increased spatial resolution of HyMap ( $5 \mathrm{~m}$ ) over such imagery as AVIRIS ( $20 \mathrm{~m}$ ) has been valuable in geobotanical studies of the caldera because smaller pixels provide for less mixing and therefore more accurate classifications.

We successfully discriminated previously mapped treekill populations with the HyMap imagery as indicated in Fig. 2c and $2 \mathrm{~d}$. Most of the robust populations are located directly to the west of Horseshoe Lake. Past fieldwork suggests that the diffuse treekill mapped to the west by HyMap is a real feature. We will ascertain the validity of this zone and other possible kills in the coming summer 2000 field season.

Future work with the treekill populations will include advanced processing techniques such as those used with clay alteration mapping in this region. Spectral endmembers of predominately kaolinite, alunite, and montmorillinite have been mapped along both known and previously unknown faults on the southern flanks of Mammoth Mtn. The inherent variability in vegetation has made such advanced processing more difficult, but the identification of both physiological state and species is possible.

\section{REFERENCES}

[1] Farrar, C. D., Sorey, M. S., Evans, W. C., Howle, J. F., Kerr, B. D., Kennedy, B. M., King, C. -Y., and Southon, J. R., "Forest-killing diffuse $\mathrm{CO}_{2}$ emission at Mammoth Mountain as a sign of magmatic unrest", Nature, v. 376, 675-677, 1995.

[2] Langbein, J., Dzurisin, D., Marshall, G., Stein, R., and Rundle, J., "Shallow and peripheral sources of inflation revealed by modeling two-color geodimeter and leveling data from Long Valley Caldera, California, 19881992," Journat of Geophysical Research, v. 100, 12,497$12,495,1995$.

[3] De Jong, S, M, "Surveying dead trees and $\mathrm{CO}_{2}$-induced stressed trees using AVIRIS in the Long Valley Caldera", in Summaries of the Sixth Annual JPL Airborne Earth Science Workshop. JPL Publication 96-, 67-74, 1996.

[4] Hausback, B. P., Strong, M., Farrar, C., and Pieri, D. "Monitoring of volcanogenic $\mathrm{CO}_{2}$-induced tree kills with AVIRIS image data at Mammoth Mountain", California, in Summaries of the Seventh Annual JPL Airborne Earth Science Workshop. JPL Publication 98-, 1998.

[5] Sorey, M. L., Evans, W. C., Kennedy, B. M., Farrar, C. D., Hainsworth, L. J., and Hausback, B., "Carbon dioxide and helium emissions from a reservoir of magmatic gas beneath Mammoth Mountain, California", Journal of Geophysical Research, v. 103, $15,303-15,323,1998$.

[6] Gao, B. C., Heidebrecht, K.B., and Goetz, A.F.H., "Derivation of scaled surface reflectances from AVIRIS data", Remote Sensing of Environment, v. 44, 165178,1993 .

[7] Boardman, J., "Post-ATREM polishing of AVIRIS apparent reflectance data using EFFORT: a lesson in accuracy versus precision", in Summaries of the Seventh Annual JPL Airborne Earth Science Workshop, JPL Publication 97-21,1998.

[8] Green, A. A., Berman, M., Switzer, P., Craig, M. D., "A transformation for ordering multispectral data in terms of image quality with implications for noise removal", IEEE Transactions on Geoscience and Remote Sensing, v. 26, no.1, pp. 65-74, 1988.

Work performed under the auspices of the U.S. Department of Energy by the University of California, Lawrence Livermore National Laboratory under Contract No. W-7405-Eng-48. 